\title{
POTENTIAL ANTIFUNGAL ACTIVITY OF ESSENTIAL OILS AND THEIR APPLICATION IN FOOD PRESERVATION
}

\author{
RAJESH SINGH TOMAR, BHAWNA SHARMA, SHUCHI KAUSHIK, RAGHVENDRA KUMAR MISHRA*
}

Amity Institute of Biotechnology, Amity University, Gwalior, Madhya Pradesh, India. Email: rkmishra@gwa.amity.edu

Received: 22 December 2017, Revised and Accepted: 13 April 2018

\begin{abstract}
The quality of food is highly affected by different types of biological, chemical, and physical contaminants. Microbial contaminations that are transferred through direct or indirect pathways such as through saliva, pest droppings, blood, or fecal matter affect the quality of food worldwide. Food can be spoiled by bacteria as well as fungus. The fungal microbes secrete toxins to intoxicate the food material rendering it unfit for consumption. The objective of the present review is to explore the application of essential oil (EO) as potent antifungal agent and thus good sources of food preservative. We have reviewed previously published papers on antimicrobial activity of EOs. The antimicrobial activity of these natural plant products has been assayed by different approaches. Apart from their activity against microbes, the other beneficial effects of these plant products such as antioxidant activity and enhancing the food quality are also observed by various groups of scientists all over the globe. On the basis of results obtained by different researchers worldwide, the EOs can be authenticated as a food preservative. For the preservation of food, several chemicals are being used by different food industries at large scale; however, they have some limitations. Recently much attention has been directed toward the development of less or negligibly toxic ethno-products which may be utilized for human use for several purposes such as food preservatives, in cosmetics, and medicines. The plant-based volatile EOs and non-volatile secondary metabolites have wide applications in dietary supplements, food flavoring and preservation, folk medicine, and fragrance industry. Several reports have confirmed the antioxidant efficacy of plant-based EOs in vitro and in vivo. Application of plant materials as dietary supplements and preservatives is mainly due to their antioxidant, antimicrobial, and other biological as well as pharmaceutical potentials. Nowadays, EOs and their components are gaining increased attention because of their relatively safe status, their wide acceptance by consumers and the possibility of their exploitation for potential multipurpose uses. It will be relevant to extract E0s, since these extracted oils may have antimicrobial potential which can be utilized for their possible roles against food spoilage microbes.
\end{abstract}

Keywords: Essential oils, Aspergillus flavus, Antimicrobial activity, Antifungal, Secondary metabolites.

(C) 2018 The Authors. Published by Innovare Academic Sciences Pvt Ltd. This is an open access article under the CC BY license (http://creativecommons. org/licenses/by/4. 0/) DOI: http://dx.doi.org/10.22159/ajpcr.2018.v11i5.24383

\section{INTRODUCTION}

With the rapidly increasing population of the world, it has become necessary for countries to store perpetual amount of food commodities to satisfy the hunger of growing world population. The contamination of food spoiling microorganisms in stored food commodities is becoming a concern of food industries. In tropical countries, food crises are mainly occurring due to spoilage of food caused by storage pests. Food and agriculture organization (FAO) has reported that every year $25 \%$ of agricultural food is quantitatively and qualitatively loses due to microbial contamination in food commodities and toxic metabolite they produce $[1,2]$.

Mold infestation cause increase in production of free fatty acids, change in texture and color, reduction in quality, germination ability, and nutritional value of grain. Stored food is contaminated by insects, viruses, and bacteria, especially by fungus. There are different types of fungus contaminating food grains such as Aspergillus, Penicillium, Fusarium, and Trichophyton. Among all the food contaminating species of Aspergillus, Aspergillus flavus has drawn a significant amount of attention of scientific society because these species have the ability to secret aflatoxin in infected food commodities in optimal environmental conditions. Aflatoxin is known for its carcinogenic nature affecting both animals and humans. A. flavus is cosmopolitan; hence, production of aflatoxin has been regarded as unavoidable contamination by the World Health Organization in food. Molds infestation and aflatoxin production in stored food commodities are a health threat to livestock and humans. Along with fungal contamination and mycotoxins production, food is also subjected to lipid peroxidation. Aflatoxin induces the production of free radicals (reactive oxygen species [ROS]), these free radical species cause the oxidation of lipid; oxidized lipid has harmful effect on human health [3]. Hence, using a single method to control fungal growth, mycotoxins production, and lipid peroxidation, food spoilage caused due to these factors can be prevented economically. The antifungal drugs which are being used suffer from a large number of drawbacks involving drug-drug interaction, development of drug-resistant fungal strain, high cost, reduction in fungicidal efficacy, and toxicity due to the repeated use of antifungal drugs. Large numbers of antifungal drugs are being introduced recently, but still, these are not sufficient to effectively control the fungal infestation. This increases the demand to develop new novel antifungal drugs which are less toxic and more effective than the drugs which are being used.

Aromatic plants are reported to be used in folk medicines from ancient time as an antimicrobial agent. Essential oils (EOs) extracted from these plants are used as an antimicrobial agent, having an ability to hinder the growth of microbes, but the activity spectrum and mode of action remains anonymous for the majority of them [4]. There is a limited amount of information available on EOs activity against human fungal pathogens, some of them have shown significant antifungal activity toward dermatophyte fungi, yeast and Aspergillus strain, which can be used in therapeutics, primarily on diseases involving respiratory tract, skin disease, and mycosis. As plant-based food preservative EOs are mostly accepted by the consumer because these are volatile and biodegradable secondary metabolites [5]. There are 17,000 known species of EOs producing aromatic compounds, generally belonging to the angiosperms these families are Rutaceae, Lamiaceae, Zingiberaceae, Asteraceae, and Myrtaceae. Their synthesis and storage take place in complex structures, namely, resins ducts, glandular trichomes, and secretary cavities. 
EOs natural plant-based food preservative

EOs are plant-based volatile and aromatic liquids. These are extracted from flowers, stem, root, leaves, peel, bark, and buds of the plants [6-8]. EOs are being used from centuries as flavoring agents, in perfumery as aromatic agents, and in medicine as antimicrobial agents. About 3000 EOs are known recently in which 300 EOs are used in fragrance and flavouring market [9]. These are secondary metabolites secreted by the plant as defense mechanism against plant infecting microbes $[10,11]$. Hence, EOs has antifungal, antiviral, insecticidal, and antiparasitic properties. EO use as a food preservative requires complete and detail study on their properties, i.e., minimum inhibitory concentration, its mode of action, its ability to target organisms. It is difficult to identify the most active compound of EOs in its mixture because it is complex mixture of more than 45 different compounds and their composition may vary according to the changing season and different methods which are being used for harvesting [12]. EOs constituents are organic compounds, and the molecular weight is very low. EOs is the combination of numerous bioactive compounds, namely, phenolic, terpenoids, terpenes, and sesquiterpenes. These are synthesized in cell cytoplasm and plastids by melonic cycle, methyl-D-erythritol-4phosphate, and mevalonic cycle. These components are divided into four groups: Terpenes, phenylpropenes, terpenoids, and others. Lots of studies have been done on EOs mode of action, and by knowing their constituents' compounds activity spectrum and mechanism of action, it becomes easier to understand their antimicrobial activity.

Terpenes are a combination of large number of isoprene units. These are synthesized from acetyl-coA through mevalonic pathway in the cytoplasm of the plant cell. Phenylpropenes form subfamily in the different group of phenylpropanoid which is synthesized from phenylalanine amino acid in plants. Its name is originated from six carbon compound containing phenol group and three carbon containing propene tail. Some examples are Eugenol and cinnamaldehyde.

Terpenoids are formed by adding oxygen and removing or adding methyl group from terpenes. They can be further divided into ester, alcohol, aldehyde, ketone, epoxides, and phenols. Some examples are thymol, menthol, and linalool [13].

\section{Food spoilage problem of world}

Food spoilage is defined as a metabolic process that makes food undesirable and unfit for consumption due to its sensory changes in its characteristics. These sensory changes in food are unacceptable olfactory, color, flavor, and visual and tactile properties [14]. Spoilage of food can occur at any stage of the food chain. It can arise due to any reason such as physical damage, insect damage, and enzymatic activity in plant tissue or in animal tissue or microbial infection. Most naturally occurring products have limited life period. Some of them can be stored for a longer time, but it decomposes ultimately. Enzymes can destruct polymers in food, some are spoiled due to rancidity and decomposition, but main reason for food spoilage is due to microorganism's invasion such as bacteria, yeast, and mold. Bacterial infection is much more dangerous than any other because food seems to be appearing normal but it may be heavily infected. The filamentous fungi that do not produce larger size fruiting bodies are known as molds. Appearance of furry growth which makes food fluffy and smells bad is due to growth of mold on it [15]. Along with microbial contamination agricultural commodities are also spoiled due to oxidative deterioration due to the production of mycotoxins by molds.

\section{Food spoiling fungus $A$. flavus}

Aspergillus is one of the largest genus having 180 accepted species. In comparison to other fungi, the taxonomy of Aspergillus is quite complex and constantly evolving. It is easily characterized by its conidiophores, but identification and determination are quite difficult because of a traditional method based on morphological characters. Macromorphological characters include colony color, colony diameter, soluble pigments, exudates production, and presence of cleistothecia and scleretia. Micromorphological characters are size and shape of vesicles, stripe and conidia morphology, morphology of ascospores, and cleistothecia [16]. Its subgenus Circumdati subdivision Flavi also known as A. flavus has attracted large amount of attention toward itself due to its industrial use and toxic effect. Flavi is further divided into two species. First one includes aflatoxin producing species A. flavus, Aspergillus nomius, and Aspergillus parasiticus. These species are producing problems in agriculture by infecting agri-food commodities. Second group of species which does not produce aflatoxin includes Aspergillus sojae, Aspergillus tamar, and Aspergillus oryzae. These species are traditionally used in Asia for fermentation process [17].

A. flavus is a pathogenic, saprophytic cosmopolitan fungus. It is mainly known for its ability to colonize in legumes, cereals, and tree nuts. It infects crop in both post-harvest and pre-harvest situations. A. flavus colonize the plants while it is in the field but does not show any symptoms until its storage and transport after harvesting as the fungus is in its dormant state [18]. Its distribution is worldwide due to its ability to produce a large number of conidia which easily gets dispersed by the air current. Atmospheric conditions plays important role in its growth in which humidity is the chief variable component. Optimal temperature for its growth is $37^{\circ} \mathrm{C}$, but its growth can be observed from $18^{\circ} \mathrm{C}$ to $48^{\circ} \mathrm{C}$, this high-temperature range makes it pathogenic for humans [19]. It is main causal organism of chronic and acute invasive and granulomatous sinusitis. It is an agent of systematic and pulmonary infection, keratitis in patients, aspergillosis, and cutaneous aspergillosis in some other vertebrates. Micromorphological features for identification are conidiophores of $1 \mathrm{~mm}$ length, colorless, thick walled and roughened; conidia are sub-globose to globose varying from 3.4 to $4.4 \mu \mathrm{m}$ in diameter, vesicles are expanded in length but become globose and sub-globose ranging in diameter from $10 \mu \mathrm{m}$ to $65 \mu \mathrm{m}$. Toxin secreted by the fungus is known as a mycotoxin.

\section{Aflatoxin and its harmful effects}

A. flavus produces mycotoxins; these are secondary metabolites potentially harmful for animals and humans. A. flavus and A. parasiticus are prime producers of aflatoxin and responsible for crop contamination [20]. Among 16 structurally associated toxins, the four major types of aflatoxins are aflatoxin $\mathrm{B}_{1}\left(\mathrm{AFB}_{1}\right), \mathrm{B}_{2}\left(\mathrm{AFB}_{2}\right), \mathrm{G}_{1}\left(\mathrm{AFG}_{1}\right)$, and $G_{2}\left(A_{B} G_{2}\right)$. These are classified on the bases of their fluorescence color, $\mathrm{B}$ for blue color, and $\mathrm{G}$ for green under ultraviolet light. $\mathrm{AFB}_{1}$ has drawn attention because it is a powerful hepatocarcinogenic and toxic natural compound that has been characterized by scientific groups [21].

Other toxins produced by A. flavus are aspergillic acid, aflatrem, gliotoxin, aspertoxin, and cyclopiazonic. $\mathrm{M}_{1}$ is another mild toxin produced by dairy animals which are consumers of aflatoxin. Aflatoxin is one of the most studied toxins because not only it causes clinical toxicosis but it also reduces resistance against the disease and interferes with the passive immunity in poultry animals [22].

The illness it caused is referred to as aflatoxicosis which rarely causes death but is mainly responsible for liver injury; some other symptoms are edema, hemorrhage, and change in nutrient absorption, and metabolism of the body which causes malnutrition. Chronic exposure to moderate or low aflatoxin is much more problematic than acute one because it causes problems related to immunity and liver in humans and $\mathrm{AFB}_{1}$ becomes a reason for liver cancer in humans. To prevent the infection caused by this toxin-producing fungus, the agriculturally developed countries screen food products time to time so as to limit its harmful effects. However, it is a major problem in developing countries because in homegrown crop aflatoxin contamination level is not checked; hence, 4.5 billion people are exposed to it globally. It makes it impossible to avoid at a low level (SAGE publication, 2015). These toxins are unavoidable contaminants in food; however, their low concentration is usually tolerable in grains, seed, and other crops. Its tolerable contamination range is $20 \mathrm{ppm}$ in grain and $100 \mathrm{ppm}$ in maize used for animal feed. Not only animals but it also affects plants by inhibiting the nucleic acid, some enzymes and protein synthesis, carotenoid and chlorophyll synthesis, seedling growth, seed germination, and root elongation [23]. 


\section{Aflatoxin induce production of free radical generation}

In recent few years free radicals are reported to have a harmful effect on health. These are produced as a part of normal metabolism in our body [24]. Free radicals defined as atom or molecule contain one or more than one electrons in the outer most shell and can exist independently. Consumption of contaminated food can damage tissues due to overproduction of ROS. Oxidative deterioration of the cell membrane due to lipid peroxidation causes cell death. Oxygen plays a dual role in our body; it is essential for organism's survival and also damages cell oxidative processes. Proteins, DNA, and RNA are the most sensitive molecules subjected to oxidative damage. $\mathrm{AFB}_{1}$ induces the generation of free radicals which becomes responsible for cell death. Aflatoxin continuous exposure causes generation of a large amount of reactive oxygen species which induces chain reaction in the body. Hence, it is necessary to hinder these steps to stop ROS formation [25]. Large numbers of synthetic medicines are being used as antioxidants to counteract the ill effects of these free radicals and thus increase the economic burden of treatment.

\section{Eugenol an effective antifungal component in EO}

Syzygium aromaticum commonly called clove is about 8-12 m long and belongs to the family Myrtaceae. It is habitually cultivated $200 \mathrm{~m}$ above sea level in coastal areas, and flowering occurs after 4 years of plantation. Buds are collected before flowering in maturation phase. The collection is done either manually or chemically using ethylene [26]. Clove is one of the major sources which provide phenolic compounds such as hydroxybenzoic acid, hydroxyphenyl propane, hydroxycinnamic acids, and flavonoids. Its main compound is eugenol found in a major amount ranging in concentration from 9380 to $14655.56 \mathrm{mg}$ in $100 \mathrm{~g}$ fresh pulp of plant material. Phenolic compounds have been reported as major constituents of several other spices also, these are bioactive compounds. Its major constituent is eugenol (80-95\%). Eugenol is the main constituent phenolic compound of clove EO and also found in some other plants EOs also. It has antifungal [27], antibacterial [28], and antiviral [29] properties. Eugenol is 4-allyl-2-methoxyphenol, having short chain of hydrocarbon attached with methoxyphenyl. Eugenol is used in dental as antiseptic due to its effect is like detergent and in spices because it has strong odor. Its sublethal concentration inhibits fungal growth by inhibiting the protease and amylase synthesis. To inhibit cellular growth eugenol breaks the cell with a high degree of cell wall deterioration [30].

Eugenol is regarded as harmless and safe compound by FAO of United Nation, with antimicrobial activity and ingestion limit of $2.5 \mathrm{mg} / \mathrm{kg}$ according to body weight (FAO 1982). Multiple methods are being used to check eugenol activity for inhibiting $A$. flavus growth, as an antioxidant and antifungal compound.

\section{CONCLUSION}

With the increasing population of earth it has become necessary to store perpetual amount of food to control the hunger of growing population. Different methods are being used for food storage but the problem arises when that stored food is contaminated by different pests. Moreover, all types of food spoiling, pesticides also cause great spoilage of food during storage and transportation. Among all these, Aspergillus is found to be the biggest problem as it not only grows in food but it also produces toxin; $\mathrm{AFB}_{1}$ which is hepatocarcinogen and thus induces the formation of cancer in consumers. The $\mathrm{AFB}_{1}$ also oxidize fatty acids and generate free radicals which also has adverse effects. In spite of using modern methods to prevent food from getting spoiled, these methods are not effective due to their side effects on consumers' health. Now use of EOs as a natural food preservative is being increasingly appreciated and welcomed by the society because of its less or negligible side effects on human health.

\section{ACKNOWLEDGMENT}

We wish to express our sincere acknowledgement to Dr. Ashok Kumar Chauhan, President, RBEF parent organization of Amity University Madhya Pradesh (AUMP), Dr. Aseem Chauhan, Additional
President, RBEF and chairman of Amity University Gwalior Campus, Lt. Gen. V.K. Sharma, AVSM (Retd.), Vice Chancellor of AUMP Gwalior Campus, for providing necessary facilities, their valuable support, and encouragement throughout the work.

\section{CONFLICTS OF INTEREST}

RST and SK contributed equally \& both are first author. The authors declare that they have no conflicts of interest.

\section{REFERENCES}

1. Tomar RS, Sharma P, Mishra RK. Evaluation of chemical composition, antioxidant property and antimicrobial activity of plant based essential oils. Eur Acad Res 2014;2:5777-98.

2. Chandra H, Farooq AA. Lipoxygenase inhibitory, antioxidant and antimicrobial activities of selected essential oils. Asian J Pharm Clin Res 2014;7:79-83.

3. Dagnas S, Membré JM. Predicting and preventing mold spoilage of food products. J Food Prot 2013;76:538-51.

4. Patnaik S, Rout K, Pal S, Panda PK, Mukherjee PS, Sahoo S. Essential oils of aromatic and medicinal plants as botanical biocide for management of coconut eriophyid mite (Aceria guerreronis Keifer). Psyche 2011;2011:1-5.

5. Lixandru BE, Drăcea NO, Dragomirescu CC, Drăgulescu EC, Coldea IL, Anton L, et al. Antimicrobial activity of plant essential oils against bacterial and fungal species involved in food poisoning and/or food decay. Roum Arch Microbiol Immunol 2010;69:224-30.

6. Deans SG, Ritchie G. Antibacterial properties of plant essential oils. Int J Food Microbiol 1987;5:165-80

7. Hammer KA, Carson CF, Riley TV. Antimicrobial activity of essential oils and other plant extracts. J App Microbiol 1999;86:985-90.

8. Sánchez E, García S, Heredia N. Extracts of edible and medicinal plants damage membranes of vibrio cholerae. Appl Environ Microbiol 2010;76:6888-94.

9. Burt S. Essential oils: Their antibacterial properties and potential applications in foods--a review. Int J Food Microbiol 2004;94:223-53.

10. Amri JE, Badaoui KE, Haloui Z. The chemical composition and the antimicrobial properties of the essential oil extracted from the leaves of Teucrium capitatum L. Asian J Pharm Clin Res 2017;10:112-5.

11. Tajkarimia MM, Ibrahima SA, Cliverb DO. Antimicrobial herb and spice compounds in food. Food Control 2010;21:1199-218.

12. Djenane D, Yanguela J, Montanes L, Djerbal M, Roncales P. Antimicrobial activity of Pistacia lentiscus and satureja montana essential oils against Listeria monocytogenes CECT 935 using laboratory media; efficacy and synergistic potential in minced beef. Food Control 2011;22:1046-53.

13. Hyldgaard M, Mygind T, Meyer RL. Essential oils in food preservation: Mode of action, synergies, and interactions with food matrix components. Front Microbiol 2012;3:1-24.

14. Burkepile DE, Parker JD, Woodson CB, Mills HJ, Kubanek J, Sobecky PA, et al. Chemically mediated competition between microbes and animals: Microbes as consumers in food webs. Ecology 2006;87:2821- 31

15. Rawat S. Food spoilage: Microorganisms and their prevention. Asian J Plant Sci Res 2015;5:47-56.

16. Rodrigues P, Santos C, Venâncio A, Lima N. Species identification of Aspergillus section Flavii solates from Portuguese almonds using phenotypic, including MALDI-TOF ICMS, and molecular approaches. J Appl Microbiol 2011;111:877-92.

17. Kumeda Y, Asao T. Heteroduplex panel analysis, a novel method for genetic identification of Aspergillus Section Flavi strains. Appl Environ Microbiol 2001;67:4084-90.

18. Amaike S, Keller NP. Aspergillus flavus. Annu Rev Phytopathol 2011;49:107-33.

19. Hedayati MT, Pasqualotto AC, Warn PA, Bowyer P, Denning DW. Aspergillus flavus: Human pathogen, allergen and mycotoxin produce. Microbiology 2007;153:1677-92.

20. Yu J, Whitelaw CA, Nierman WC, Bhatnagar D, Cleveland TE. Aspergillus flavus expressed sequence tags for identification of genes with putative roles in aflatoxin contamination of crops. FEMS Microbiol Lett 2004;237:333-40.

21. Bennett JW, Klich M. Mycotoxins. Clin Microbiol Rev 2003;16:497- 516.

22. Sharma RP. Immunotoxicity of mycotoxins. J Dairy Sci 1993;76:892-7.

23. Jones HC, Chancey JC, Morton WA, Dashek WV, Llewellyn GC. 
Toxic responses of germinating pollen and soybeans to aflatoxins. Mycopathologia 1980;72:67-73.

24. Sisein EA. Biochemistry of free radicals and antioxidants. Sch Acad J Biosci 2014;2:110-8

25. Saiketsen S, Chakroborty R, Sirdhar S, Reddy Y, Biblab D. Free radicals, antioxidants, diseasesa and phytomedicines: Current status and future prospect. Inc J Pharm Sci Rev Res 2010;3:91-100.

26. Kamatou GP, Vermaak I, Viljoen AM. Eugenol-from the remote Maluku islands to the international market place: A review of a remarkable and versatile molecule. Molecules 2012;17:6953-81.

27. Shashidar NS. Studies on Bioactive Natural Compounds for their
Antimicrobial and Antioxidant Properties. In Ph. D. Thesis Dept. of Microbiology. Hyderabad: Osmania University; 2012

28. Sen P, Maiti PC, Puri S. Mechanism of antistress activity of Ocimum sanctum Linn, eugenol and Tinospora malabaria in animals. Ind J Exp Biol 1992;30:592-6

29. Pacheco P, Sierra J, Schmeda-Hirschmann G, Potter CW, Jones BM, Moshref M. Antiviral activity of Chilean medicinal plant extracts. Phytother Res 1993;7:415-8.

30. Thoroski J, Blank G, Biliaderis C. Eugenol induced inhibition of extracellular enzyme production by Bacillus cereus. J Food Prot $1989 ; 52: 399-403$ 